\title{
Knowledge and Attitude of Dental interns about Oral Health Considerations in patients with Renal Problems in Davanagere city: A cross sectional survey
}

\author{
Puja C Yavagal ${ }^{1 *}$, Veeresh D J ${ }^{2}$, Anindita Dutta ${ }^{3}$, Habakordor Syiem ${ }^{4}$, Naavisha Subamanium ${ }^{5}$, \\ Normah Mohd ${ }^{6}$ \\ ${ }^{1,2}$ Professor, ${ }^{3}$ Post Graduate, ${ }^{4}$ Under Graduate, ${ }^{5,6}$ Intern, Dept. of Public Health Dentistry, Bapuji Dental College and \\ Hospital, Davanagere, Karnataka, India
}

*Corresponding Author: Puja C Yavagal

Email: pujacyavagal@gmail.com

\begin{abstract}
Introduction: Knowledge of Dental intern about oral health problems in patients with renal problems is essential to take precautions to avoid bactaeremia and prevent complications in term.

Aim: To assess the knowledge and attitude of dental interns about oral health considerations in patients with renal problems.

Materials and Methods: A cross sectional questionnaire survey was done among 146 dental interns of Davanagere city.

Data was collected using a validated and pretested 14 item questionnaire. First 8 items (1-8) and rest seven were designed to assess knowledge and attitudes of interns respectively. Responses were recorded on a three point Likert scale. Scores were assigned to knowledge scores ranging between 0-19.

Statistical analyses: Descriptive statistics was generated in terms of frequencies and percentages. Chi-square test and student's unpaired t test were used for data analysis. Statistical significance was set at $p<0.05$.

Results: The mean age of the study participants was $23.99 \pm 0.86$ years. The mean knowledge score of the study participants was $9.74 \pm 0.8$ which reflected fair knowledge of dental intern regarding oral health problems among patients with renal problems. Majority of interns felt the need for consultation and consent of nephrologist before treating renal patients. They underlined the importance of avoiding nephrotoxic drugs, prophylactic antibiotic coverage before dental treatment, mandatory preoperative investigations and risk of transmission of infections. They felt the need to get educated regarding dental treatment considerations in such patients.

Conclusion: Dental schools must design teaching modules to train the interns in effective dental treatment and management of patients with renal problems.
\end{abstract}

Keywords: Attitude, Knowledge, Dental interns, Renal Diseases.

\section{Introduction}

Various medical conditions can affect the oral health of patients. With advances in medical treatment and improved survival rates for many disorders, dentists can be expected to treat an increasing number of patients with complex medical conditions. Prevalence of Renal diseases is a worldwide public health problem resulting in high cost and poor outcomes. ${ }^{1}$ As a consequence of a number of uremic metabolic, endocrinological, and immunological imbalances, chronic kidney disease (CKD) patients suffer from numerous systemic complications that may contribute to poor oral health. ${ }^{2}$ Although there are no specific signs in the oral cavity indicating the presence of Renal Disease a whole range of changes occur in the oral cavity that are associated with renal diseases therapy. ${ }^{3-5}$

Renal diseases can give rise to a wide spectrum of oral manifestations in the hard and soft tissues. They may lead to the development of pale oral mucosa, dental calculus, enamel hypoplasia, dry mouth, low caries rate, poor oral hygiene, and uremic stomatitis, and may cause changes in the salivary composition and flow rate. These complications can lead to excessive bleeding, anemia, increased susceptibility to infection, drug intolerance, renal osteodystrophy, adrenal crisis, and enamel defects in children. ${ }^{1}$

Oral cavity is a potential diagnostic tool in the clinical assessment of systemic health. Poor oral health in patients with renal disease is an important problem but is often ignored. Signs of poor oral health and dentition should be considered with caution at early stages of renal disease. ${ }^{6}$ Oral manifestations that have been reported in patients with renal problems include ammonia-like odor resulting from a high urea content, gingivitis, xerostomia, mucosal pallor, tooth mobility, malocclusion, and a greater risk of dental erosion due to frequent regurgitation. ${ }^{7}$ These problems may be related to a variety of factors, such as a relative state of immunosuppression, medication, renal osteodystrophy and bone loss and restriction of oral fluid intake. 
Primary preventive measures for patients undergoing dialysis for kidney failure have previously been overshadowed by concerns about more urgent health problems. Dental health appears to be yet another area where attention has been lacking. ${ }^{5}$ Thorough knowledge of the oral changes in such patients is essential to diagnose the underlying disease and to take precautions to avoid bacteremia and prevent complications.

Promoting good dental hygiene reduces the risk of oral infections that may predispose a patient to septicaemia, endocarditis and possible endarteritis of the vascular access or line for haemodialysis or of catheters for peritoneal dialysis. For a variety of reasons, nutrition may be a significant problem for dialysis patients, and this condition can be exacerbated by ill- fitting oral prosthetic devices, carious or missing teeth and local infections. Good oral health is important in patients with renal problems given the immunosuppressive protocols that may further predispose to oral and possibly disseminated infection. ${ }^{5}$ Dental Schools should train the students in identifying oral health problems in such patients and effectively managing them. Studies which assess their knowledge regarding treatment considerations in patients with renal problems will help dental schools to plan teaching modules which may help dentists in effectively managing such patients and improve their health. Hence, a study was planned with the aim to assess the knowledge and attitude of dental interns about oral health considerations in patients with renal problems.

\section{Materials and Methods}

A descriptive cross sectional questionnaire survey was conducted. Ethical permission was sought from the Review board of Dental College and Hospital where the study was conducted. Permission was obtained from college authorities. Voluntary written informed consent was obtained from the study participants after explaining them about the purpose of conducting the study by using a participant information form. The data was collected from interns of two dental colleges in the city of Davanagere. Study involved purposive whole sample that is 103 dental interns population of two dental colleges in Davanagere city. Inclusion criteria were, Dental interns who gave voluntary informed written consent and interns present on the date of data collection. The data was collected from the interns at their respective college premises.

\section{Description of questionnaire}

Research questionnaire was pretested, validated, selfadministered questionnaire containing two sections in the English language. This survey was completed during regularly scheduled class sessions. The 14-item questionnaire consisted of two sections; Section one had the provision to record demographic details (name, age, gender and college address). Section two included questions to assess the knowledge and attitude of Dental Interns about oral health considerations in patients with renal problems. Considering the two main constructs (knowledge, attitude), 14 items were framed. First 8 items (1-8) were designed to assess the knowledge of the participants regarding oral conditions commonly reported in patients with renal diseases and management of such patients during dental procedures.Item 1 assessed the knowledge of the participants regarding twelve oral conditions commonly reported in patients with renal diseases. Responses to all items were placed on 3 point Likert scale. The scores for all items assessing knowledge were summed up which represented the knowledge score of the participant. 6 items (Item number 9-14) were designed to assess the attitudes of the participants regarding dental treatment considerations of patients with renal diseases the responses of which were on a 3 point Likert scale. Content validity of the questionnaire was assessed by five experts: Public health dentist, Nephrologist, Oral Medicine and Radiologist, General physician and Intern. Questionnaire was assessed for relevance, simplicity, clarity and ambiguity. The Content Validity Index score for relevance, simplicity, clarity and ambiguity was $0.7,0.8,0.8$ and 0.8 respectively.

\section{Procedure of data collection}

Participants were asked to assemble in the lecture hall on scheduled day. The self-administered questionnaire was distributed to them by an investigator. Participants were instructed not to discuss any answers with their friends. They were also instructed to approach investigator if they had any doubts pertaining to questionnaire. The participants were given 20 minutes to answer the questionnaire. Later questionnaire was collected back by checking for the complete response.

\section{Statistical Analyses}

The data obtained was compiled systematically in Microsoft Excel sheet and subjected to statistical analysis using Statistical Package for Social Sciences Software. Descriptive statistics was generated in terms of frequencies and percentages. Data was analysed 
using chi-square test for categorical data. Comparison of knowledge scores between groups was done using student's unpaired t test. Statistical significance was set at $\mathrm{p}<0.05$.

\section{Results}

The mean age of the study participants was $23.99 \pm 0.86$ years. Majority of them were females $(67.1 \%)$ There was almost equal representation of subjects from both the colleges. The mean knowledge score of the study participants was $9.74 \pm 0.8$ which reflected fair knowledge regarding oral health problems among patients with renal problems. Around $40-76 \%$ of subjects were aware about oral health problems related to renal diseases. However more than half of them felt mucosal petechiae and malignancy were not associated with renal diseases. (Table 1)

Almost $80 \%$ of interns felt the need for consultation and consent of nephrologist before treating renal patients and felt that nephrotoxic drugs should not be prescribed for such patients. More than half of them felt the need of prophylactic antibiotic coverage before dental treatment and necessity of mandatory preoperative investigations. Many of them were aware of the ideal time to treat renal patients. (Table 2)

Though $76 \%$ of them felt the risk of transmission of infections $92.5 \%$ of them considered treating such patients. Around $91 \%$ felt the need to get educated regarding dental treatment considerations in such patients.(Table 3) Gender wise comparison of knowledge and attitude of dental interns about oral health considerations in patients with renal problems revealed that there was no significant difference ( $t$ 0.75. $\mathrm{p}=0.74$ ) between mean knowledge scores among males $(9.97 \pm 2.2)$ and females $(9.70 \pm 2.03)$. Significantly more number of female interns $(68 \%)$ felt the need to get educated regarding dental treatment considerations in renal patients than males (33\%) (chi Square value $=4.14, \mathrm{p}=0.03$ )

Table 1: Knowledge of study participants about oral health problems in patients with renal diseases

\begin{tabular}{|l|c|c|c|c|c|c|}
\hline \multirow{2}{*}{ Question } & \multicolumn{3}{c|}{ Type of Response of Dental Interns } \\
\cline { 2 - 7 } & \multicolumn{2}{|c|}{ Yes } & \multicolumn{2}{c|}{ No } & \multicolumn{2}{c|}{ Don't know } \\
\hline $\begin{array}{l}\text { Oral health problems associated } \\
\text { with renal diseases }\end{array}$ & Frequency & Percentage & Frequency & Percentage & Frequency & Percentage \\
\hline Ammonia like breath & 112 & $76.7 \%$ & 21 & $14.4 \%$ & 13 & $8.9 \%$ \\
\hline Metallic taste & 62 & $42.5 \%$ & 54 & $37 \%$ & 30 & $20.5 \%$ \\
\hline Gingivitis & 93 & $63.7 \%$ & 34 & $23.3 \%$ & 19 & $13 \%$ \\
\hline Periodontitis & 89 & $61 \%$ & 34 & $23.3 \%$ & 23 & $15.8 \%$ \\
\hline Xerosomia & 82 & $56.2 \%$ & 49 & $33.6 \%$ & 15 & $10.3 \%$ \\
\hline Stomatitis & 59 & $40.4 \%$ & 52 & $35.6 \%$ & 35 & $24 \%$ \\
\hline Dental erosion & 63 & $43.2 \%$ & 36 & $24.7 \%$ & 47 & $32.2 \%$ \\
\hline Candidiasis & 60 & $41.1 \%$ & 47 & $32.2 \%$ & 47 & $32.2 \%$ \\
\hline Mucosal Petechiae & 23 & $15.8 \%$ & 74 & $50.7 \%$ & 49 & $33.6 \%$ \\
\hline Mucosal lesion & 77 & $52.7 \%$ & 27 & $18.5 \%$ & 42 & $28.8 \%$ \\
\hline Oral Malignancy & 24 & $16.4 \%$ & 91 & $62.3 \%$ & 31 & $21.2 \%$ \\
\hline Radiographic features & 53 & $36.3 \%$ & 74 & $50.7 \%$ & 19 & $13 \%$ \\
\hline
\end{tabular}

Table 2: Knowledge of dental interns regarding treatment considerations in patients suffering from renal diseases

\begin{tabular}{|c|c|c|c|c|c|c|}
\hline \multirow[b]{3}{*}{ Variables } & \multicolumn{6}{|c|}{ Type of Response of Dental Interns } \\
\hline & \multicolumn{2}{|c|}{ Yes } & \multicolumn{2}{|c|}{ No } & \multicolumn{2}{|c|}{ Don't know } \\
\hline & Frequency & Percentage & Frequenc & Percentage & Frequency & Percentage \\
\hline $\begin{array}{lllr}\text { Consultation } & \text { and } & \text { consent } & \text { with } \\
\text { Nephrologist } & \text { is } & \text { needed } & \text { during } \\
\text { treatment } & & & \\
\end{array}$ & 120 & $82.2 \%$ & 14 & $9.6 \%$ & 12 & $8.2 \%$ \\
\hline $\begin{array}{l}\text { Prophylactic antibiotic treatment } \\
\text { indicated before dental procedure }\end{array}$ & 88 & $60.3 \%$ & 44 & $30.1 \%$ & 14 & $9.6 \%$ \\
\hline Avoid prescribing nephrotoxic drugs & 117 & $80.1 \%$ & 17 & $11.6 \%$ & 12 & $8.2 \%$ \\
\hline $\begin{array}{l}\text { Investigations mandatory before dental } \\
\text { procedures }\end{array}$ & 104 & $71.2 \%$ & 25 & $17.1 \%$ & 17 & $11.6 \%$ \\
\hline $\begin{array}{l}\text { Best time to do dental procedures is } \\
\text { the day after dialysis }\end{array}$ & 83 & $56.8 \%$ & 42 & $28.8 \%$ & 21 & $14.4 \%$ \\
\hline $\begin{array}{l}\text { Elective dental treatment should not be } \\
\text { done in the first six months after renal } \\
\text { transplantation }\end{array}$ & 91 & $62.3 \%$ & 42 & $28.8 \%$ & 13 & $8.9 \%$ \\
\hline
\end{tabular}




\begin{tabular}{|l|l|l|l|l|l|l|}
\hline $\begin{array}{l}\text { AV shunt should not be disturbed and } \\
\text { the affected area should never be used } \\
\text { for IV and IM injections }\end{array}$ & 79 & $54.1 \%$ & 46 & $31.5 \%$ & 21 & $14.4 \%$ \\
\hline
\end{tabular}

Table 3: Attitude of dental interns regarding treatment considerations in patients suffering from renal diseases

\begin{tabular}{|c|c|c|c|c|c|c|}
\hline \multirow[t]{3}{*}{ Attitudes } & \multicolumn{6}{|c|}{ Type of Response of Dental Interns } \\
\hline & \multicolumn{2}{|c|}{ Yes } & \multicolumn{2}{|c|}{ No } & \multicolumn{2}{|c|}{ Don't know } \\
\hline & Frequency & Percentage & Frequency & Percentage & Frequency & Percentage \\
\hline $\begin{array}{l}\text { After consultation } \\
\text { nephrologist would } \\
\text { treatment }\end{array}$ & 135 & $92.5 \%$ & 3 & $2.1 \%$ & 8 & $5.5 \%$ \\
\hline $\begin{array}{l}\text { Feel the risk of transmission and cross } \\
\text { transmission of diseases }\end{array}$ & 111 & $76.0 \%$ & 22 & $15.1 \%$ & 13 & $8.9 \%$ \\
\hline $\begin{array}{l}\text { Consultation mandatory with Nephrologist } \\
\text { before prescribing medications }\end{array}$ & 127 & $87.0 \%$ & 14 & $9.6 \%$ & 5 & $3.4 \%$ \\
\hline $\begin{array}{l}\text { Feel the need to get educated regarding } \\
\text { dental treatment considerations in renal } \\
\text { patients }\end{array}$ & 133 & $91.1 \%$ & 8 & $5.5 \%$ & 5 & $3.4 \%$ \\
\hline $\begin{array}{l}\text { Need to prevent bacteraemia in patients with } \\
\text { renal problems }\end{array}$ & 114 & $78.1 \%$ & 18 & $12.3 \%$ & 14 & $9.6 \%$ \\
\hline $\begin{array}{l}\text { Need to get educated regarding oral hygiene } \\
\text { maintenance among renal patients }\end{array}$ & 114 & $78.1 \%$ & 11 & $7.5 \%$ & 21 & $14.4 \%$ \\
\hline
\end{tabular}

\section{Discussion}

Renal disease has become important in dentistry due to the growing number of patients who, as a result of renal dialysis or transplantation, survive renal failure. Aspects of renal disease affecting dental management are heparinization before dialysis, possible hepatitis B or $\mathrm{C}$ carriage after chronic dialysis, permanent venous fistulae susceptible to infection, secondary hyperparathyroidism, immunosuppressive treatment for nephritic syndrome or transplant patients, oral lesions due to drugs, particularly for immunosuppression, low doses or withholding of many drugs: for example, cephalosporins and tetracycline and oral lesions of chronic renal failure. ${ }^{2}$ Renal dialysis leads to systemic alterations and oral complications. Studies have shown higher rates of oral pathology in patients with renal problems. ${ }^{5-8}$ Both gingivitis and periodontitis are seen more frequently in renal patients. Gingival hyperplasia is a relatively common periodontal complication in renal transplantation patients that has been attributed to cyclosporine dosage and the presence of dental plaques, likely contributing to gingival inflammation. [3] Patients with renal failure often complain of ammonia-like bad odour because of the high urea content in saliva and its subsequent breakdown to ammonia. Increased dental calculus has been observed as a consequence of a high salivary urea and phosphate levels. ${ }^{4} \mathrm{~A}$ spectrum of oral mucosal lesions like white and erythematous patches, lichen planus-like disease, oral hairy leukoplakia etc. have been found in patients with renal problems due to drug-related immunosuppression or an associated drug. ${ }^{5}$ Thorough knowledge of oral changes in patients suffering from renal disease is essential to diagnose the underlying disease and to take precautions to avoid bacteraemia and prevent complications in such patients. Hence a study was conducted among dental interns to assess the knowledge and attitude of dental interns about oral health considerations in patients with renal problems.

Results of the study indicated that the knowledge regarding the oral health problems associated with renal disease was fair among study participants. These results are contrary to results of the study done by Newadkar et al where knowledge among dental students was poor. ${ }^{9}$ About $84 \%$ of students were unaware of investigations to be advised in patients suffering from renal diseases. Perhaps the reason could be because of the difference in the experience of students. The present study was done among interns while the study done by Nedwadkar et al included third and final year dental undergraduate students. Interns might have improved knowledge based on increased exposure to teaching hours as well as clinical training in dental colleges and majority of them would be studying for postgraduate exams which would require them to study extensively regarding systemic diseases and its impact on oral health. Around $40-76 \%$ of subjects were aware about oral health problems related to renal diseases like Uremic breath, metallic taste, gingivitis, periodontitis, xerostomia, stomatitis, dental erosion, candidiasis and mucosal lesions. Proper management of such oral health problems in patients suffering from renal diseases would significantly improve their quality of 
life and positively influence the dental treatment prognosis. Many students were aware about avoidance of nephrotoxic drugs in such patients. Similar results were seen in study done by Newadkar et al where dental students were aware about the pharmacological considerations in patients suffering from renal diseases. ${ }^{[9]}$ It is necessary to implement the clinical suspicion of oral health considerations in patients with renal problems throughout the undergraduate course to enable awareness and early diagnosis. Close collaboration between the dentist and nephrologist is required in the treatment of patients with chronic renal disease as it might reduce the risk of oral infections and improve the dental treatment prognosis. Dental schools should periodically train the undergraduate students to recognize the oral health problems and its effective management in patients with renal diseases. The survey had few limitations. The sample was convenient hence generalizability was compromised. Oral health is often compromised in patients with renal problems and may contribute to, inflammation, infections, and atherosclerotic complications, all of them important problems that would justify an increased attention to dental care and a better awareness in the clinic. Maintaining a healthy and functional dentition in such patients is challenging to dentists. Poor oral health should be considered with great caution even at very early stages of chronic renal disease, in dialysis patients, and in patients undergoing kidney transplantation. Finally, unsatisfactory daily oral hygiene habits and insufficient awareness of the importance of oral health apparently warrants the combined and coordinated efforts of both dentists and nephrologists towards improving the quality of life of their patients.

\section{Conclusions}

Dental interns had fair knowledge regarding oral health problems among patients with renal diseases. Majority were aware of oral health problems related to renal diseases and pharmacological and treatment considerations in such patients. They strongly expressed need for consultation and consent of nephrologist before treating renal patients. Though interns felt the risk of transmission of infections, they considered treating such patients. Interns felt the need to get educated regarding dental treatment considerations in such patients. Hence dental schools must design teaching modules periodically to train the undergraduate students in the diagnosis of oral health problems and effective dental treatment and management of patients with renal problems.

\section{Source of funding}

None.

\section{Conflict of interest}

None.

\section{References}

1. Eknoyan G, Lameire N, Barsoum R, Eckardt KU, Levin A, Levin $\mathrm{N}$ et al. The burden of kidney disease: improving global outcomes. Kidney Intl 20041;66(4):1310-4.

2. Souza CM, Braosi AP, Luczyszyn SM, Casagrande RW, Pecoits-Filho R, Riella MC et al. Oral health in Brazilian patients with chronic renal disease. Rev Med Chil 2008;136(6):741-6.

3. Vesterinen M, Ruokonen H, Leivo T, Honkanen AM, Honkanen E, Karl K et al. Oral health and dental treatment of patients with renal disease. Quintessence Int 2007;38(3).

4. Summers SA, Tilakaratne WM, Fortune F, Ashman N. Renal disease and the mouth. Am J med 2007;120(7):56873.

5. Klassen JT, Krasko BM. The dental health status of dialysis patients. J Can Dent Assoc 2002;68(1):34-8.

6. Akar H, Akar GC, Carrero JJ, Stenvinkel P, Lindholm B. Systemic consequences of poor oral health in chronic kidney disease patients. Clin J Am Soc Nephrol 2011;6:218 $-26$.

7. Tozoglu U, Keles M, Unal D, Uyanik A. Cytological analysis of the oral cells of chronic renal failure patients: A cytomorphometric study. Turk J Med Sci 2012;42:1443-8.

8. de la Rosa García E, Padilla AM, Romo SA, Ramírez MA. Oral mucosa symptoms, signs and lesions, in end stage renal disease and non-end stage renal disease diabetic patients. Medicina oral, patología oral y cirugía bucal. $E d$. Inglesa 2006;11(6):3.

9. Newadkar UR, Chaudhari GL. Knowledge and attitude of dental students about oral health considerations in patients with renal problems. SRM J Res Dent Sci 2017;8(2):69.

How to cite: Yavagal PC, Veeresh DJ, Dutta A, Syiem H, Subramanium N, Mohd N. Knowledge and Attitudes of Dental Interns about oral health considerations in patients with renal problems in Davanagere city: A cross sectional survey. Int Dent J Student Res 2020;8(1):22-6. 